\title{
Article
}

\section{Human Disease/Clinical Medical Sciences in Dentistry: Current state and future development of undergraduate assessments in the UK and Ireland}

Atkin, P.A., Willis, A., Doncahie, C., Elledge, ROC, Thomas, S.J., Riordain, R Ni, Galvin, S., Marney, C., Setterfield, J.F., Smith, P.M. and Hammond, Douglas

Available at http://clok.uclan.ac.uk/31913/

Atkin, P.A., Willis, A., Doncahie, C., Elledge, ROC, Thomas, S.J., Riordain, R Ni, Galvin, S., Marney, C., Setterfield, J.F. et al (2020) Human Disease/Clinical Medical Sciences in Dentistry: Current state and future development of undergraduate assessments in the UK and Ireland. European Journal of Dental Education, 24 (3). ISSN 1396-5883

It is advisable to refer to the publisher's version if you intend to cite from the work. /10.1111/eje.12519

For more information about UCLan's research in this area go to http://www.uclan.ac.uk/researchgroups/ and search for < name of research Group>.

For information about Research generally at UCLan please go to http://www.uclan.ac.uk/research/

All outputs in CLoK are protected by Intellectual Property Rights law, including Copyright law. Copyright, IPR and Moral Rights for the works on this site are retained by the individual authors and/or other copyright owners. Terms and conditions for use of this material are defined in the policies page. 


\section{Human Disease/Clinical Medical Sciences in Dentistry: Current state and future development of undergraduate assessments in the UK and Ireland}

Atkin PA

Department of Oral Medicine, Cardiff University, Cardiff, UK

atkinpa@cardiff.ac.uk

\section{Willis A}

Department of Oral Medicine, Queens University Belfast, Belfast, UK

a.willis@qub.ac.uk

\section{Doncahie C}

Department of Special Care Dentistry, University of Aberdeen, Aberdeen, UK cdonachie@abdn.ac.uk

\section{Elledge ROC}

College of Medical and Dental Sciences, University of Birmingham, Birmingham, UK r.o.c.elledge@birmingham.ac.uk

\section{Thomas SJ}

Department of Oral \& Maxillofacial Surgery, Bristol University, Bristol, UK

Steve.thomas@bristol.ac.uk

\section{Ni Riordain R}

Department of Oral Medicine, University College Cork, Cork, Ireland richeal.niriordain@ucc.ie

\section{Galvin S}

Department of Oral Medicine, Trinity College, University of Dublin, Dublin, Ireland

This article has been accepted for publication and undergone full peer review but has not been through the copyediting, typesetting, pagination and proofreading process, which may lead to differences between this version and the Version of Record. Please cite this article as doi: $\underline{10.1111 / \text { EJE.12519 }}$

This article is protected by copyright. All rights reserved 
galvinsh@tcd.ie

Marney C

Department of Oral Medicine, University of Dundee, Dundee, UK cmarney@dundee.ac.uk

\section{Setterfield JF}

Department of Oral Medicine, King's College London, London, U.K. Jane.setterfield@kcl.ac.uk

\section{Smith PM}

School of Dental Sciences, University of Liverpool, Liverpool, UK petesmif@liverpool.ac.uk

Hammond D

School of Dentistry, University of Central Lancashire, Preston, UK dhammond1@uclan.ac.uk 
DR. PHILIP A ATKIN (Orcid ID : 0000-0001-6718-8106)

Article type : Original Article

\section{Abstract}

Introduction

The United Kingdom and Ireland teachers of Human Disease/Clinical Medical Science for Dentistry (HD/CMSD) group continues to work together, and most recently collaborated to review current and future assessments.

Materials and methods

The first part of the review of assessments in HD/CMSD took place at a face-to-face meeting with presentations from delegates on assessments in their home institutions. The second, and larger part, comprised an online survey where all eighteen schools in the UK and Ireland participated.

Results

All schools had some element of formative assessment, and the majority had a stand-alone summative assessment at the end of the HD/CMSD teaching block. Most schools had a written paper and practical elements to their assessments, most commonly a combination of a multiple-choice type question combined with an objective structured clinical examination (OSCE). There was a trend towards the use of single best answer (SBA) 
questions and a willingness among participants to share a question bank. All schools incorporated elements of HD/CMSD in their final examinations.

\section{Discussion \& Conclusion}

This collaboration promoted the sharing of developments in assessment for HD/CMSD and demonstrated a willingness to co-operate between institutions. Assessment in HD/CMSD in the UK and Ireland continues to be refined by those responsible for its content and delivery and assessment methods are progressing following evidence-based best practice.

Keywords

Clinical medical sciences in dentistry

Human disease

Medicine and surgery

Undergraduate

Assessment

Examination

\section{Data availability statement}

The data that support the findings of this study are available on request from the corresponding author. The data are not publicly available due to privacy or ethical restrictions.

This article is protected by copyright. All rights reserved 


\section{Main Text}

\section{Introduction}

The UK and Ireland Teachers of Human Disease/Clinical Medical Science (HD/CMSD) is an informal group of interested colleagues who work cooperatively to develop and progress teaching and assessment in their respective institutions and foster best practice. Previously the group has worked to develop a curriculum for $\mathrm{HD} \mathrm{CMSD}^{1}$, and more recently, the group looked at the content and delivery of the HD/CMSD curriculum ${ }^{2}$. This latest meeting and survey focussed on how assessments for HD/CMSD are being delivered and any likely future developments. A recent meeting of the Association for Dental Education in Europe (ADEE) in partnership with the American Dental Education Association (ADEA) looked at dental assessments in a global context ${ }^{3}$, and how the paradigm of 'assessment drives learning' might shift to 'assessment for learning'. The Teachers Group of HD/CMSD is conscious of how current assessment might foster the former approach, but by shaping future formative and summative assessments, we may move towards the latter. This might then encourage a deeper understanding of the role of human health and disease may play in in the safe and effective delivery of general dentistry and special care dentistry, among other specialties, in the context of an ageing population with increasing morbidity and polypharmacy. A recent report on the extent of chronic disease in Europeans of retirement age stated: "The burden of chronic diseases on Europeans of retirement age is substantial and will increase due to population ageing and prevailing lifestyle risks" ${ }^{4}$. This is the population our new dental graduates will serve, and a thorough understanding of human health and disease is key.

\section{Materials and Methods}

Whether formal research ethics committee (REC) approval was required for the voluntary, online survey data collection was considered by the principal organisers (PA and AW), however, as described in the paper by Buchanan ${ }^{5}$ (a participant in this study) "The research 
design involved non-sensitive questionnaire surveys, and participants were not considered to be "vulnerable." Participation was not anticipated to be likely to cause either psychological stress or anxiety, and no detrimental impact ... was foreseen. As such, it was considered to be exempt from formal ... REC approval." This was a cooperative study with interested professional clinicians and educators, which would be to the benefit all of those participating. The subsequent sharing and dissemination of the results to the immediate group and to a wider audience was considered a valuable goal.

A meeting was convened where representatives of eleven of the eighteen UK and Ireland dental schools each presented a summary of the current state of their HD/CMSD assessments, both formative and summative, as well as a short description of how their assessments had developed to this point and where their future may lie.

In addition HD/CMSD teachers from all schools in the UK and Ireland took part in an online questionnaire survey ${ }^{6}$ looking at assessments, with questions on exam styles, standard setting, input from external and internal examiners and school staff, use of formative and summative assessments, where in the undergraduate programme HD/CMSD assessments took place and how much support for HD/CMSD was forthcoming.

The first part of the online survey collected basic demographic details about the participants; their qualifications, specialty backgrounds and how long they had been involved in the organisation and coordination of the HD/CMSD programme in their dental school. Later questions asked over which years the HD/CMSD course extended and when and how formative assessments were carried out, and who compiled the assessment and who was involved in the marking. Questions also focussed on summative assessments, how they were composed, delivered, standard-set and marked, and whether they were integrated into other assessments or were stand-alone examinations and what overall contribution they made to professional Bachelor of Dental Surgery (BDS) examinations in the course. Questions also looked at the contributions from external examiners and their background and experience. Another section of the questionnaire asked about future cooperation between the teachers of HD/CMSD - if a common assessment method could be 
agreed on, whether a pooled question bank was possible and if a single, nationally-agreed HD/CMSD summative assessment would be supported. The final group of questions asked about the support for HD/CMSD the group felt they had in general and in particular for formative and summative assessment in their schools. Within the questionnaire, as well as clicking on an answer from a choice of responses there were opportunities to complete text boxes to clarify and expand on answers.

\section{Results}

Survey participants

Of the eighteen respondents who were involved in the assessment of HD/CMSD in the dental schools of the UK and Ireland, thirteen were both dentally and medically qualified, four were singly-dentally qualified and one had qualifications in physiology and in education with a lead teaching and assessment role in their dental school. Of the clinically-qualified participants, nine $(50 \%)$ were specialists in oral medicine, five $(28 \%)$ were maxillofacial surgeons, and there was one each with specialist training in special care dentistry, oral surgery and oral pathology. All were consultants and/or clinical academics of varying degrees of seniority ranging from clinical lecturers to professors. In terms of their duration of involvement with HD/CMSD teaching and assessment in their institutions, exactly half $(n=9,50 \%)$ reported between one and three years, a third $(n=6,33 \%)$ more than ten years, and the remainder from between four and nine years.

Across the dental schools, the HD/CMSD teaching was mostly delivered over the second, third and fourth years, and there were formative assessments mostly in these same years.

Formative assessments

Formative assessment styles were described by most respondents, and typically there was a mix of assessment types and styles. Six schools used single best answer (SBA) questions, five used workbooks/logbooks or case reflections in their formative assessments, and other formative assessments included multiple choice questions (MCQ), objective structured clinical examinations (OSCE) and short answer questions (SAQ). When asked who wrote, set 
and marked the formative assessments, eight of the fourteen (57\%) who made additional comments, reported that as the lead for HD/CMSD, they did the work. Others were aided by delegated lecturers in the dental school, or lecturers on the HD/CMSD course from medical and surgical specialties.

Summative assessments at the end of the HD/CMSD programme

Fourteen schools had stand-alone summative assessments in HD/CMSD. The question styles in the stand-alone summative examination were asked about, with the majority using a combination of SAQs, EMQs and MCQs (Figure 1). Fourteen schools reported using OSCEs in the summative assessment, with the majority using actors/simulated patients in at least some of the stations. Information regarding the number of OSCE stations was not requested but some respondents provided the information as follows: one school had 12 stations, another 10 stations and a third 3 stations. The remaining respondents did not specify the number of stations. Additional question formats included data interpretation and HD/CMSD topics integrated into other assessments. The markers at the OSCE stations were mostly staff from the dental hospital or school (principally oral medicine, oral surgery and OMFS) as well as medical and surgical staff involved in the HD/CMSD teaching programme. When asked about the marking of the summative assessment, ten reported some electronic marking (typically SBAs and MCQs), and twelve reported marking by hand (SAQs, OSCEs). The hand-marked assessments were mostly all double-marked, or a sample from the highest, lowest and borderline grades were double marked.

Figures 2, 3 and 4 describe aspects of support for creation and marking of summative assessments and how they are integrated into the overall BDS examinations.

Figure 5 relates to the responses relating to the perceived importance of the HD/CMSD themes in the overall BDS programme 
Standard-setting and feedback for HD/CMSD assessments

In twelve (66\%) schools the HD/CMSD lead was always involved in the standard-setting of the assessments. In the remainder (34\%), there was a mix of clinical medical and dental staff. Some respondents noted that they felt it was important that there was a mix of subject-specialists and non-subject specialists involved, including specialty registrars and staff from the dental hygiene/therapy school to "... bring an appropriate balance and perspective", and "... to involve a wide range of individuals including those from primary care." For the methods of standard-setting used in the schools, some used more than one, and in two the respondents were unsure. Sixteen (89\%) used Angoff/modified-Angoff, and one each used Ebel and Hofstee methods. In eight schools (44\%) all students received feedback from their summative assessment, seven (39\%) gave no feedback, and the remainder gave feedback to the students who failed and were to resit. Respondents gave no additional details of the feedback provided.

Summative assessments elsewhere in the undergraduate programme

Eleven (61\%) of the schools reported that elements of HD/CMSD were assessed elsewhere in the programme. All of these reported that the final degree examinations included some aspect of HD/CMSD, and a smaller number reported summative assessment included in other assessment schedules. Ten of the schools (56\%) who included a clinical case or scenario in their final examination would always include an HD/CMSD element. Two (11\%) did not, and the remainder mostly, but not always, would do this.

Shared assessments

The group was asked about collaboration and assessments. Figure 6 shows the types of questions that could be used in such an assessment, and majority felt that SBAs and SAQs would be the most useful. In the 'other' group, half thought that OSCEs would be useful addition and two thought that EMQs would be appropriate. When asked about a shared question bank for a stand-alone HD/CMSD assessment 16 of 17 respondents (94\%) were in 
favour. When asked about a single nationally-agreed summative examination paper, there was a less clear consensus (Figure 7), but with the majority agreeing in principle.

External examiners

Eleven schools (61\%) reported having an external examiner specifically for the HD/CMSD summative examination. The remainder described a policy of wherever possible having a doubly-qualified examiner in the external examiner group who would be involved in the HD/CMSD assessment as well as other topics under examination in the same diet. Seventeen (94\%) schools had the external examiner take part in the examination board for the summative HD/CMSD assessment. Ten schools (55\%) reported that their external examiner was always involved in the HD/CMSD course in their own school and a further five $(28 \%)$ said that this was not a formal requirement, but where they could they did, or used external examiners who had previous experience in this area. The remaining three $(17 \%)$ schools had no requirement that an external examiner be involved in HD/CMSD.

\section{Discussion}

There appears to be a consistent direction of travel in regard to the HD/CMSD summative assessment. Where schools were looking to update their assessments, many are moving towards SBAs for mid-BDS programme assessments, including HD/CMSD examinations. Most schools have HD/CMSD as a stand-alone assessment among other clinical topics.

In regard to end-of-programme, or final examinations HD/CMSD is present for nearly all schools. None have a stand-alone paper but questions including HD/CMSD-themes form part of the both the written and clinical assessments.

The HD/CMSD teachers group members in their individual schools continue to evolve the formative and summative assessments in the dental undergraduate programmes. The majority felt that they were well supported by their schools in the creation, standard setting 
and marking of assessments, and that the HD/CMSD elements were well integrated into the overall assessments in the undergraduate programme.

From discussion at the initial meeting, most delegates described a process of moving along a pathway of assessments that began as essay questions, logbooks from clinical attachments and case report written assignments, to a combination of written examinations using a mixture of SAQs, EMQs and MCQs alongside OSCEs. MCQ-based examinations (including EMQs) are reliable and allow a sampling of a range of student knowledge ${ }^{7}$. The sole use of MCQs is discouraged, but are valuable when used alongside other forms of assessment ${ }^{8}$, for example OSCE assessments, which have been shown to be reliable with good validity when used in dental undergraduate examinations ${ }^{9}$. SBAs have been shown to have high levels of reliability, can be machine marked very efficiently and are used across both medical undergraduate and postgraduate assessments ${ }^{10}$. Where a question, such as an SBA, includes a patient vignette, with some clinical information, the interpretation and/or problem-solving elements are thought to involve 'higher-order' skills rather than just factual recall ${ }^{11}$. Writing good SBAs with appropriate distractors takes time and effort to write, making the case for a nationally shared question bank with best-quality assessments produced from an expert group with an investment in collective production of quality SBAs.

Adoption of a common format of examination such as SBAs may lend itself to sharing of questions between institutions. In the online survey $94 \%$ of respondents were in favour of this. Several schools were already using an online assessment software platform for storing question banks, allowing for standard setting of individual SBAs and compilation of an assessment paper ${ }^{12}$, and other schools were planning to adopt this same system. This commonality may allow for ease of sharing of standard-set and trialled questions between institutions and promote some uniformity of assessment across the participating institutions.

\section{Conclusion}

The findings from the conference discussions, and from the online survey demonstrate that the teachers of HD/CMSD group are regularly reviewing the style and appropriateness of 
assessment in HD/CMSD and evolving them to the benefit of students, staff and patients.

The choice of assessment style is moving towards more reliable, reproducible and valid questions and typically with the use of an online platform.

This article is protected by copyright. All rights reserved 


\section{Acknowledgements}

The authors would like to acknowledge the contributions of our colleagues, the HD/CMSD representatives of dental schools in the UK and Ireland who kindly took the time to participate in the online survey: Alex Crighton, University of Glasgow, Alan Mighell, University of Leeds, Richard Graham, University of Manchester, Mark Greenwood, Newcastle University, Jon Bennett, University of Plymouth, John Buchanan, Queen Mary, University of London and Issam Bakri, University of Sheffield.

\section{References}

${ }^{1}$ Mighell AJ, Atkin PA, Webster K, et al. Clinical medical sciences for undergraduate dental students in the United Kingdom and Ireland -a curriculum. Eur J Dent Educ. 2011;15:179-188.

${ }^{2}$ Atkin PA, Thomas S, Cook RJ, et al. Human Disease/Clinical Medical Sciences in Dentistry:

Current state and future directions of undergraduate teaching in the UK and Ireland. Eur J Dent Educ. 2018;00:1-6.

${ }^{3}$ Patel US, Tonni I, Gadbury-Amyot C, Van der Vleuten CPM, et al. Shaping the future of dental education: Assessment in a global context: An international perspective on dental education. Eur J Dent Educ. 2018;22(Suppl. 1):21-27.

${ }^{4}$ Harbergs, M. \& Achtenberg, P. (2012). Europeans of retirement age: chronic diseases and economic activity. Netherlands: The Dutch National Institute for Public Health and the Environment (RIVM).

${ }^{5}$ Buchanan JAG, Parry D. Engagement with peer observation of teaching by a dental school faculty in the United Kingdom. Eur J Dent Educ. 2019;23:42-53.

6 Online Surveys (formerly Bristol Online Surveys). https://www.onlinesurveys.ac.uk/ (Accessed February 2019) 
${ }^{7}$ McCoubrie P. Improving the fairness of multiple-choice questions: a literature review. Med Teach. 2009;26(8):709-12.

${ }^{8}$ Anderson J. Multiple choice questions revisited. Med Teach. 2004 Mar;26(2):110-3.

${ }^{9}$ Graham R, Zubiaurre Bitzer LA, Anderson OR. Reliability and predictive validity of a comprehensive preclinical OSCE in dental education. J Dent Educ. 2013 Feb;77(2):161-7.

${ }^{10}$ Sam AH et al. Very-short-answer questions: reliability, discrimination and acceptability. Med Educ. 2018 Apr;52(4):447-455.

${ }^{11}$ Case SM \& Swanson DB (2003) Constructing written test questions for the basic and clinical sciences, $3^{\text {rd }}$ edn. Philadelphia: National Board of Medical Examiners (NBME). Available from: http://www.nbme.org/PDF/ItemWriting_2003/2003IWGwhole.pdf (Accessed July 2019) ${ }^{12}$ Liftupp. https://www.liftupp.com/ (accessed 8.6.19) 


\section{Tables/Figures}

Figure 1

Describe the format of your stand-alone (summative) HD/CMSD assessment

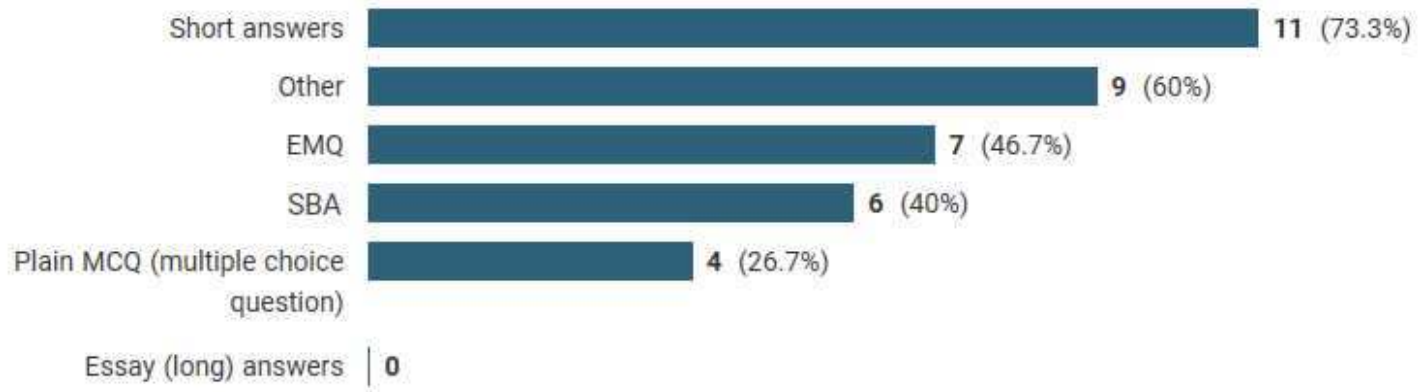

Figure 2

As the HD/CMSD lead/coordinator in my dental school, I feel well supported in the creation of summative assessment questions

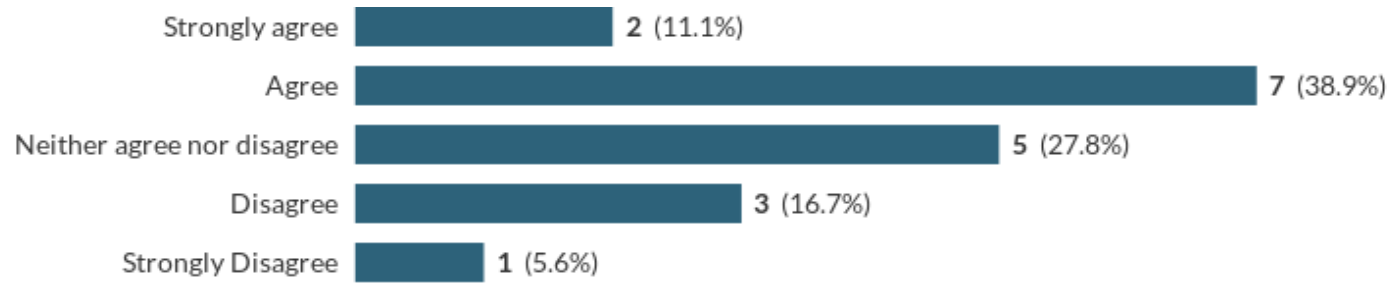

Figure 3

As the HD/CMSD lead/coordinator in my dental school I feel well supported in the marking of summative assessments

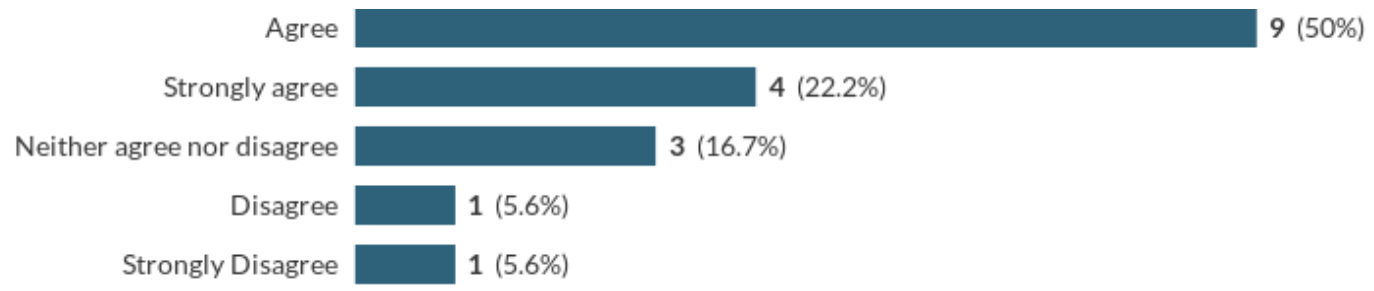

This article is protected by copyright. All rights reserved 
Figure 4

As the HD/CMSD lead/coordinator in my dental school, I feel the HD/CMSD summative assessment is well-integrated into the overall BDS examinations

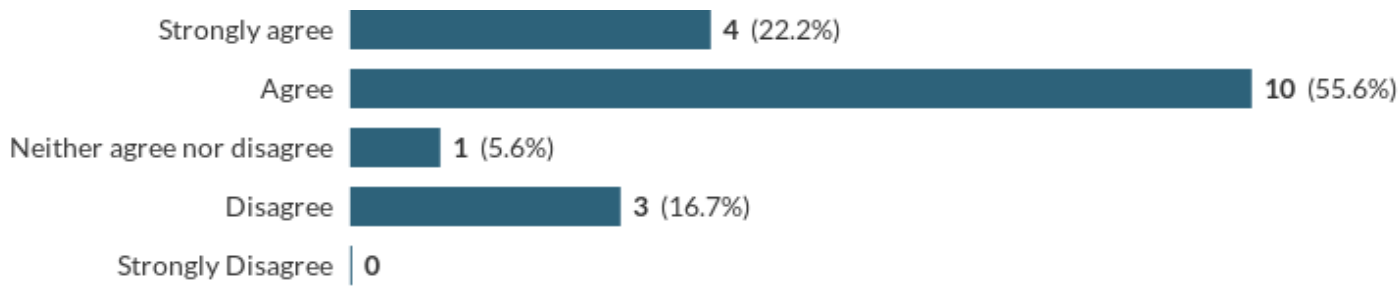

Figure 5

As the HD/CMSD lead/coordinator for my school, I feel HD/CMSD is given due importance in the overall BDS programme

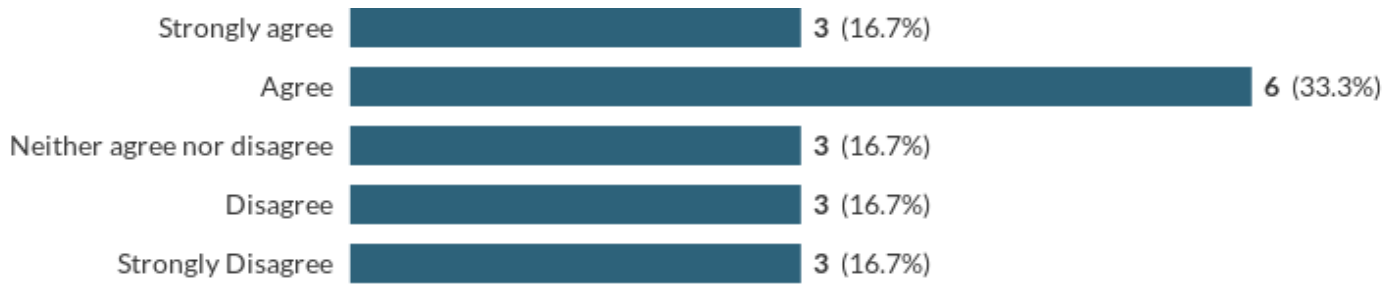

Figure 6

If the Teachers of HD/CMSD group could agree on an assessment method that could be shared across dental schools, what format do you think that assessment might take?

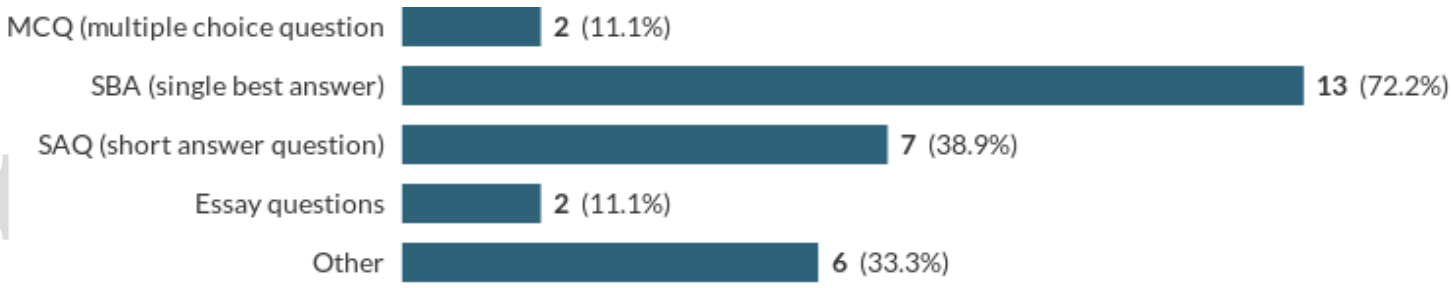

Figure 7

If the Teachers of HD/CMSD could agree a pooled question-bank, in principle, would you also consider a single, nationally-agreed summative examination?

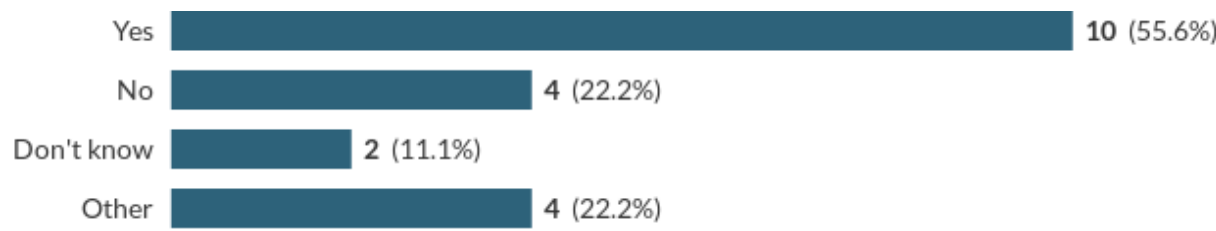

This article is protected by copyright. All rights reserved 